\title{
The Influence of Sizings on the Durability of High-Temperature Polymer Composites
}

\author{
Ronald E. Allred*, Sheldon P. Wesson*, E. Eugene Shin**, Linda Inghram**, Linda \\ McCorkle**, Demetrios Papadopoulos***, Donald Wheeler****, \\ and James K. Sutter**** \\ *Adherent Technologies, Inc., Albuquerque, NM \\ **Ohio Aerospace Institute, Cleveland, $\mathrm{OH}$ \\ ***University of Akron, Akron, $\mathrm{OH}$ \\ ****NASA Glenn Research Center, Cleveland, $\mathrm{OH}$
}

\begin{abstract}
To increase performance and durability of high-temperature composites for potential rocket engine components, it is necessary to optimize wetting and interfacial bonding between high modulus carbon fibers and high-temperature polyimide resins. Sizings commercially supplied on most carbon fibers are not compatible with polyimides. In this study, the chemistry of sizings on two high-modulus carbon fibers (M40J and M60J, Toray) was characterized as was the chemistry of PMR-II-50 fluorinated polyimide resin. The carbon fibers were characterized using single filament wetting, scanning electron microscopy, fourier transform infrared spectroscopy, and $x$-ray photoelectron spectroscopic measurements. The polyimide matrix resins were coated onto glass filaments for characterization by wetting measurements. Surface energy components were obtained by wetting with nondispersive (methylene iodide), acidic (ethylene glycol), and basic (formamide) probes. A continuous desizing system that uses an environmentally friendly chemical-mechanical process was developed for tow level fiber. Composites were fabricated with fibers containing the manufacturer's sizing, desized, and further treated with a reactive finish. Results of room-temperature tests after thermal aging show that the reactive finish produces a higher strength and more durable interface compared to the manufacturer's sizing. When exposed to moisture blistering tests, however, the better bonded composite displayed a tendency to delaminate, presumably due to trapping of volatiles.
\end{abstract}

KEYWORDS: sizing, desizing, carbon fibers, reactive finish, thermal aging, mechanical properties, wetting, surface energy, blistering, interface

\section{INTRODUCTION}

High-temperature polymer matrix composites (PMCs) are desired for many aerospace and military applications. These aggressive environments have required new blends of materials properties in the composite fiber and matrix. In that endeavor, it is often found that the sizings routinely added to commercial carbon fibers are not compatible with the new high-temperature matrix resins. The result is that the thermo-oxidative stability (TOS) and mechanical properties of composites made with such fibers are compromised. Before high-temperature PMCs can routinely be used in demanding applications, their long-term TOS must be improved. 
M40J and M60J carbon fibers available from Toray (Japan) have an unusual combination of stiffness and strength for use in high-temperature applications; however, the epoxy-compatible sizes available on these fibers may not be optimum for compatibility with high-temperature polymers. The work described here was undertaken to characterize the Toray size, to develop a means to remove the commercial size and replace it with a high temperature finish, and to determine the thermomechanical properties of polyimide composites fabricated with the various fiber surface types. Our approach was to characterize the M40J and M60J sizings using scanning electron microscopy (SEM), single filament wetting, x-ray photoelectron spectroscopy (XPS), and fourier transform infrared spectroscopy (FTIR). The Toray sizing was then removed using hot chloroform in a continuous desizing process and a high-temperature finish applied and characterized. The desized and desized/refinished fibers were also characterized using the above techniques. Cross plied composites were fabricated with PMR-II-50 matrices and tested in the thermally aged and unaged conditions. Finally, moisture blistering tests were conducted on the various laminates.

Results show that the Toray sizing is very non-uniform on the fiber surface and that it appears to be a hydroxyllated terephthalate type of polyester. Desizing in hot chloroform with ultrasound leaves mostly clean fiber with a few small (tenths of microns) nodules of residual size. The desized Toray fibers are also highly striated, creating the possibility of improved interfacial adhesion by a mechanical interlocking mechanism. Single filament wetting has shown that the sized surfaces are energetically and topographically heterogeneous. Formamide wetting shows that M40J and M60J surfaces display similar acidity whether sized or desized. Ethylene glycol wetting suggests that the size covers basic functionality that is uncovered by desizing. PMR-II50 polyimide resin is mildly amphoteric, since the acid-base component of fiber wettability $\left(\mathrm{W}^{\mathrm{a}-\mathrm{b}}\right)$ is small but finite for both acidic and basic probe liquids. The reactive finish bonds well to the desized fiber and improves interfacial adhesion before and after high-temperature aging; however, the well bonded laminates debonded in the moisture blistering tests, presumably due to internal trapping of volatiles.

\section{EXPERIMENTAL PROCEDURES}

\section{Desizing Approach}

Initial desizing studies showed that one, three, and five minutes in boiling chloroform dropped the surface oxygen content to a constant level of approximately $10 \%$. These data were used to design a continuous desizing unit shown schematically in Figure 1. The desizing unit shown in Figure 1 consists of a $7 \mathrm{~m}$ heated tube feeding in and out of each side of a bath that is irradiated with ultrasound. The entire system is filled with chloroform. For application of reactive finish, a dip bath followed by a tube furnace is placed between the desizing unit and the take-up winder. The desizing unit was operated at a speed of $3 \mathrm{~m} /$ minute. Additional information on the desizing process is given in Reference 1. 


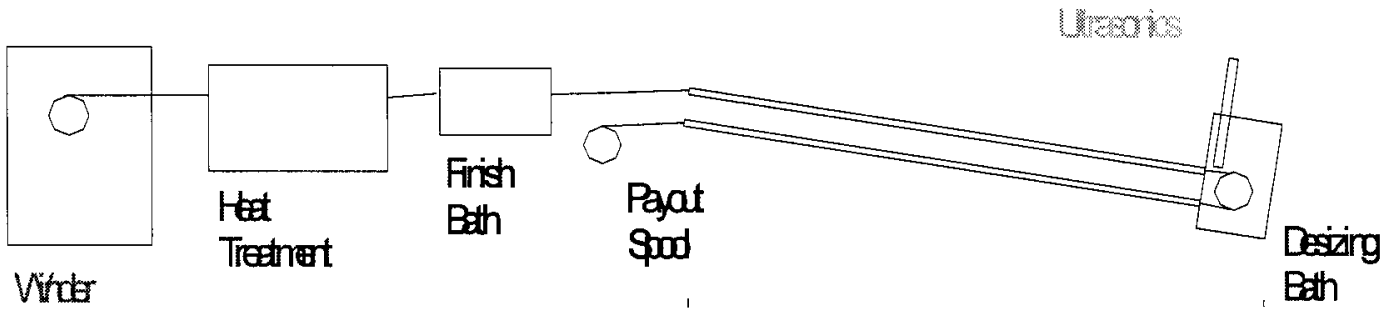

Figure 1. Schematic of $7 m$ continuous desizing unit

\section{Wetting Experiments}

Fiber surface energy characterization was performed using the Wilhelmy technique [2]. M40J and M60J carbon monofilaments were glued to metal hooks and suspended vertically from the working arm of a Cahn 2000 microbalance, while a precision elevator raised and lowered the liquid surface along $0.5 \mathrm{~mm}$ of fiber. A schematic of the wetting apparatus is given in Figure 2 .

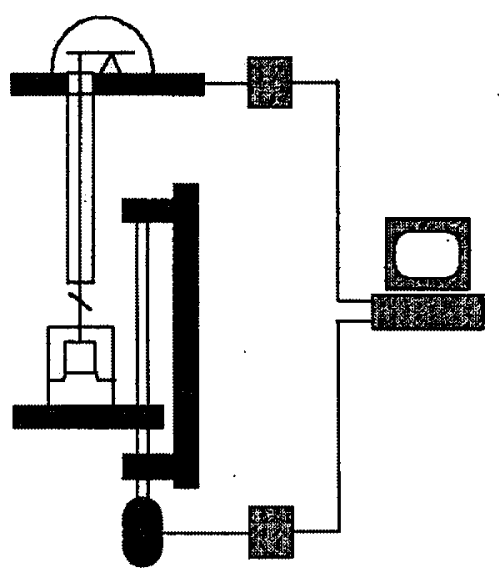

$\mathrm{F}=\mathrm{Mg}=\gamma_{1} \mathrm{p} \cos \theta$
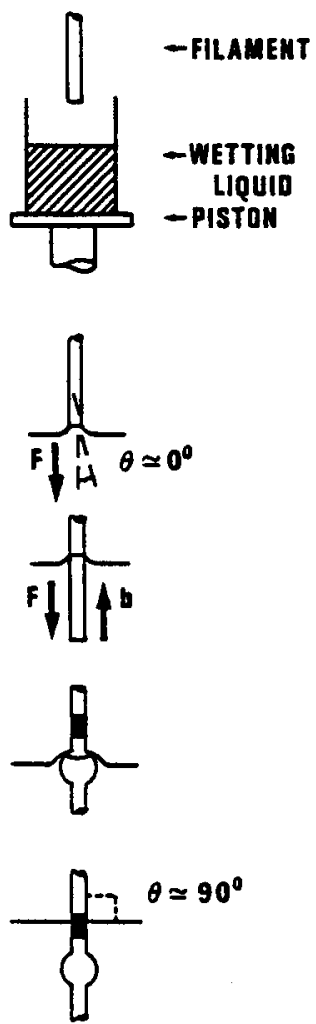

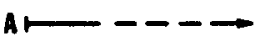

WETTIMG TRACE
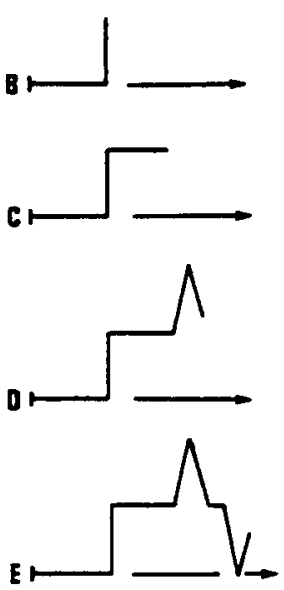

Figure 2. Schematic of Wilhelmy wetting balance and sample wetting traces

A computer periodically recorded the change in apparent mass caused by wetting forces at the three-phase boundary using the probe liquids listed in Table I. Advancing work of adhesion, 
$\mathrm{W}_{\mathrm{adv}}$, the dispersive component of fiber wettability, $\mathrm{W}^{\mathrm{d}}$, and the acid/base component of fiber wettability, $\mathrm{W}^{\mathrm{a} / \mathrm{b}}$, were computed by methods previously reported [3-6].

Table I. Surface Energy $\left(\mathrm{mJ} / \mathrm{m}^{2}\right)$ Characteristics of Probe Liquids [6]

\begin{tabular}{|c|c|c|c|}
\hline & \\
\hline & $\gamma^{\mathrm{d}}$ & $\gamma^{\mathrm{a} / \mathrm{b}}$ & $\gamma^{\mathrm{T}}$ \\
\hline Methylene Iodide $\left(\mathrm{CH}_{2} \mathrm{I}_{2}\right)$ & 48.5 & 1.7 & 50.2 \\
\hline Formamide $\left(\mathrm{HCONH}_{2}\right)$ & 39.5 & 18.7 & 58.2 \\
\hline Ethylene Glycol $\left(\mathrm{HOCH}_{2} \mathrm{CH}_{2} \mathrm{OH}\right)$ & 29.3 & 19.0 & 48.3 \\
\hline
\end{tabular}

Many of the substrate-liquid combinations spread in the receding mode and were close to spreading in the advancing mode. Since non-spreading liquids with known acid/base character, (ethylene glycol and formamide) were carefully selected for having high surface tensions, the number of additional liquid probes that could be used is severely limited. This indicates that, while wetting studies are a valuable method for surface characterization, further characterization of these surfaces requires another technique, such as inverse gas chromatography or microcalorimetry.

\section{Reactive Finish Formulation}

The reactive finishes were based on the work in Reference 7. That work and subsequent studies by the authors have shown that the reactive coupling agent chemically bonds to carbon fiber surfaces. Figure 3 depicts the structure of the proprietary 9307 coupling agent.

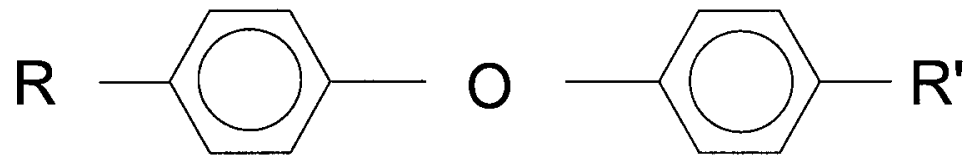

$$
R, R^{\prime}=\text { proprietary functional groups }
$$

Figure 3. Chemical structure of 9307 coupling agent

The finish formulations used $0.3 \%$ coupling agent and $3.0 \mathrm{wt} . \%$ PMR-II-50 polyimide resin in acetone. The tube furnace was set at a temperature of $250^{\circ} \mathrm{C}$ to initiate the bonding reaction with the desized M40J.

\section{XPS Analysis}

Sized, desized, and refinished M40J carbon fibers were analyzed by XPS. Survey spectra were taken to examine the as-received surface chemical stoichiometry. High-resolution spectra were taken of significant peaks seen in the survey scans to determine possible surface bonding states. 
The analyses were run at NASA Glenn Research Center using a Surface Sciences SSX-100 spectrometer with an $\mathrm{Al} \mathrm{K} \alpha$ source. $\mathrm{C}_{1 \mathrm{~s}}$ high-resolution peaks were averaged over 10 to 15 scans using a spot size of $300 \mu \mathrm{m}^{2}$ with no flood gun. $\mathrm{O}_{1 \mathrm{~s}}$ peaks were averaged over 30 scans. A Gaussian curve fitting routine was used to resolve high-resolution photopeaks into components based on binding energy references from model compounds [8]. The spectra were not charge referenced.

\section{FTIR Analysis}

A Nicolet Magna 560 FTIR spectrometer equipped with a Nic Plan microscope was used to acquire fiber sizing spectra. The microscope was operated in reflectance mode using a $32 \mathrm{X}$ objective (spot diameter $100 \mu$ ). Typically 100 scans were averaged at $4 \mathrm{~cm}^{-1}$ resolution vs. a gold microscope slide. Spectra were corrected for water and carbon dioxide.

\section{Composite Fabrication}

A new process called "tow plate-winding" was developed with a modified lathe for the fabrication of all composite panels. The tow plate-winding process is described in detail in Reference 9 . The $30 \times 30 \mathrm{~cm}$ laminated composite panels were fabricated by a typical vacuum bagging process in hot-press molding platens (applied pressure: $3.45 \mathrm{MPa}$ ) at NASA GRC using optimized PMR-II-50 cure cycles after a separate B-staging at $204^{\circ} \mathrm{C}\left(400^{\circ} \mathrm{F}\right)$ for $1 \mathrm{hr}$. All cured panels were then dried and postcured at $371^{\circ} \mathrm{C}\left(700^{\circ} \mathrm{F}\right)$ in air for $16 \mathrm{hrs}$. The fabricated PMR-II50 matrix panels were $[0,90,90,0,90,0,0,90,0,90,90,0]_{\mathrm{s}} 24-$ ply composite laminates and approximately $0.25 \mathrm{~cm}$ thick.

Initial quality of the composite panels was evaluated by ultrasonic C-scan (ULTRAPAC-AD500 , Physical Acoustics) with a $5 \mathrm{MHz}$ probe after a standard calibration with poly(methyl methacrylate). Void content and fiber volume fraction of the composites were determined by acid digestion per ASTM D 3171. The glass transition temperatures, thermal degradation temperature, coefficient of thermal expansion, and dynamic mechanical properties of the cured and postcured composites were determined by standard thermo-analysis techniques including dynamic mechanical analysis (TA Instrument 2980 DMA), thermomechanical analysis (TA Instrument 2940 TMA), and thermogravimetric analysis (TA Instrument 2950 TGA HR). Composite mechanical properties were measured using an Instron universal testing machine with a Series IX Automated Materials Testing System following ASTM D3518 and D2344.

\section{Aging Tests}

Quarter sections of the laminates were aged in an air circulating oven at $343^{\circ} \mathrm{C}\left(650^{\circ} \mathrm{F}\right)$ for various times. Following aging, $\pm 45^{\circ}$ tensile test specimens and short beam shear specimens were cut using a water-cooled diamond wheel.

Five-cm (2-inch) square blister specimens were sonicated in a cleaning agent and dried in a vacuum oven until constant weight was obtained. The specimens were then conditioned in a humidity cabinet at $60^{\circ} \mathrm{C}$ and $90 \%$ relative humidity. After the specimens maintained a constant weight, blister testing was performed. The blister tests were performed on the saturated samples at two different conditions. The first condition was at a ramp rate of $50^{\circ} \mathrm{C} / \mathrm{min}$ to a temperature of $400^{\circ} \mathrm{C}$. The second blister condition was obtained at two ramp rates. The first ramp rate of 
$5^{\circ} \mathrm{C} / \mathrm{min}$ was used up to a temperature of $250^{\circ} \mathrm{C}$ then it was increased to a ramp rate of $50^{\circ} \mathrm{C} / \mathrm{min}$ to $400^{\circ} \mathrm{C}$.

Five locations on a sample were marked to measure the thickness change before and after blister testing. A micrometer was used to measure the thickness. The schematic depicting the five locations is shown in Figure 4. Comer No. 4 was cut for photomicrograph, microcrack counts, and void calculation before exposure to humidity conditions.

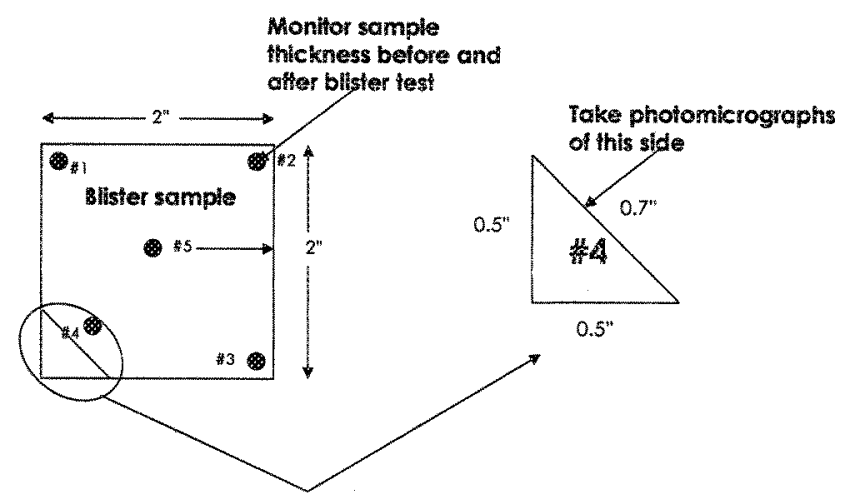

Figure 4. Schematic illustrating five different locations of a blister sample

\section{RESULTS AND DISCUSSION}

\section{Sized Fiber Characterization}

The appearance of the sized Toray M40J and M60J fibers is shown in Figure 5.
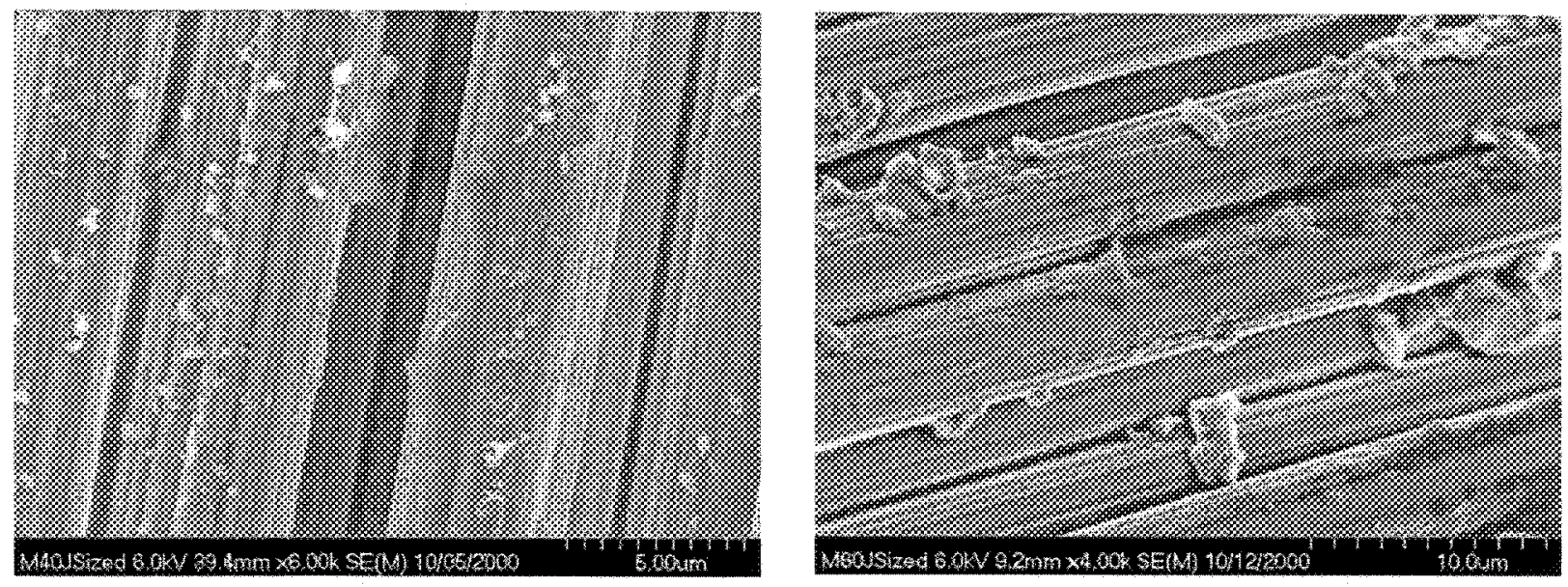

Figure 5. Appearance of sized M40J and M60J (right) carbon fibers

Figure 5 shows that the Toray size is very non-uniform in thickness and coverage on the asproduced fibers. The deep striations on the fiber surface are also seen in Figure 5.

High resolution XPS $\mathrm{C}_{1 \mathrm{~s}}$ photopeaks for the sized Toray fibers are shown in Figure 6 . Results show that the surface oxygen groups are predominately singly bound to carbon, presumably as hydroxyl moieties. The resolved data are given in Table II. 

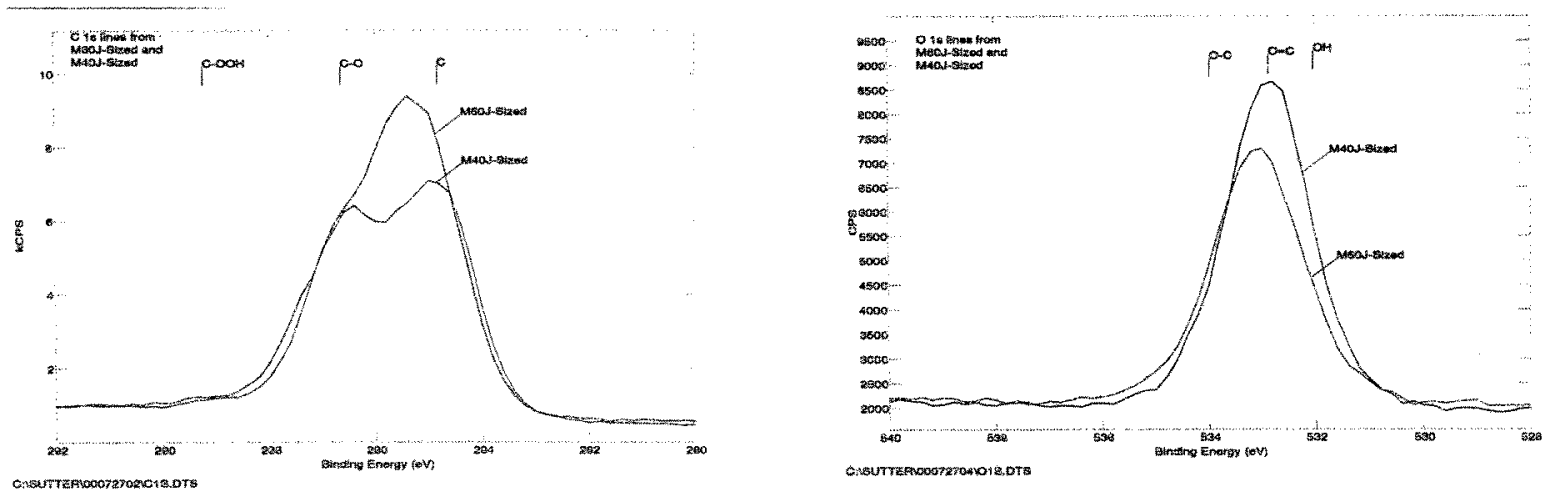

Figure 6. Comparison of high resolution $C_{l s}$ and $O_{I s}$ photopeaks for $M 40 J$ and $M 60 J$ sized carbon fibers

Table II. XPS Results for Sized Toray Carbon Fibers

\begin{tabular}{|c|c|c|}
\hline Moiety & M40J Sized & M60I Sized \\
\hline \% C-C & 39.8 & 54.7 \\
\hline$\%$ C-O & 34.4 & 26.7 \\
\hline$\%$ C-OO & 2.1 & 1.4 \\
\hline$\%$ O1s & 23.7 & 17.2 \\
\hline
\end{tabular}

Results given in Table II show that the Toray sizing has an unusually large amount of oxygencontaining moieties present mostly as single bonded C-O (hydroxyl, ester). The M60J appears to have a somewhat lower size content.

Surface reflectance FTIR spectra for the Toray sized carbon fibers are shown in Figure 7.

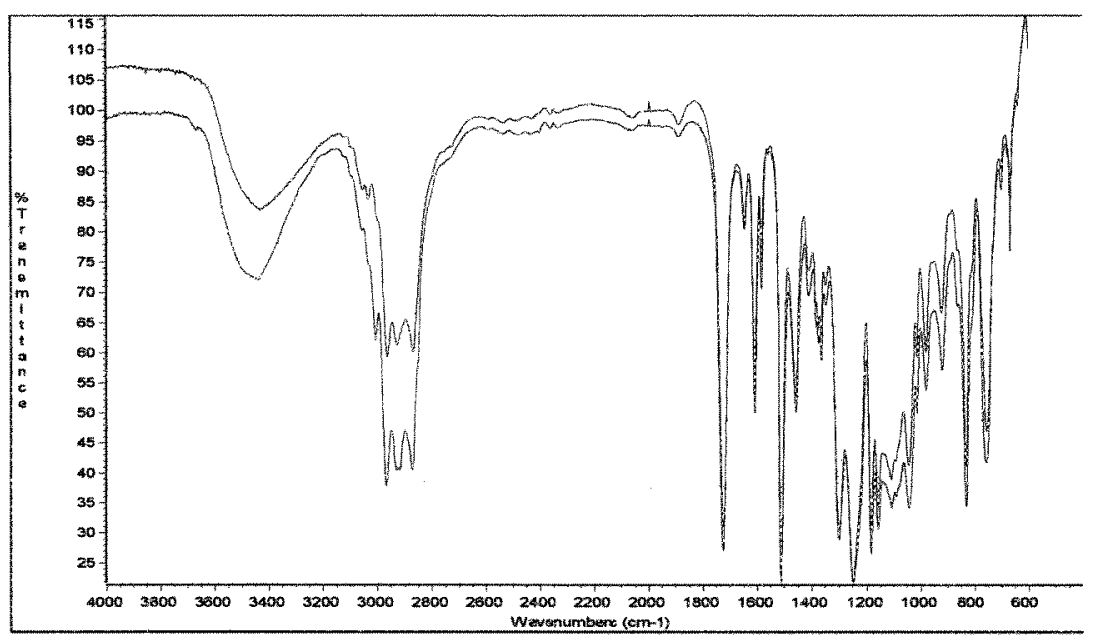

Figure 7. FTIR spectra comparing M40J (top) and M60J sized surfaces (bottom) 
In Figure 7, in addition to aliphatic and aromatic C-H stretching bands between 2800 and 3100 $\mathrm{cm}^{-1}$, a broad peak between 3200 and $3600 \mathrm{~cm}^{-1}$ is seen that is indicative of hydroxyl groups. Peaks located at 1725-1730 indicate aromatic ester carbonyl and peaks at 1250 and 1300 are C-O vibrations. It is also evident in Figure 7 that the sizings on both fibers have the same chemistry. At this point, the balance of the study was focused on the M40J fibers only.

\section{Desized Fiber Characterization}

The appearance of M40J fibers after treatment in the desizing unit with ultrasound is shown in Figure 8.
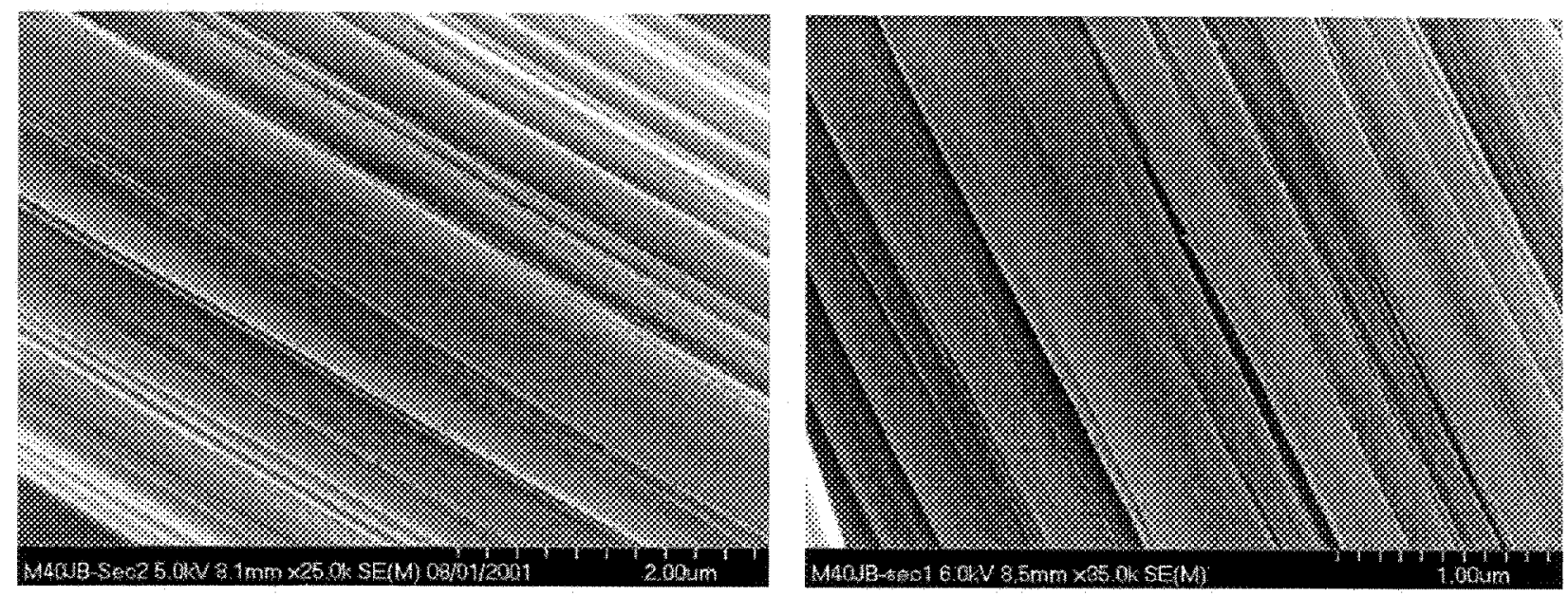

Figure 8. Appearance of continuously desized M40J carbon fiber

As seen in Figure 8, most of the sizing except persistent sub micron size nodules have been removed by the hot chloroform. High resolution $\mathrm{C}_{1 \mathrm{~s}}$ XPS photopeaks for the sized and desized M40J fiber surface are shown in Figure 9.

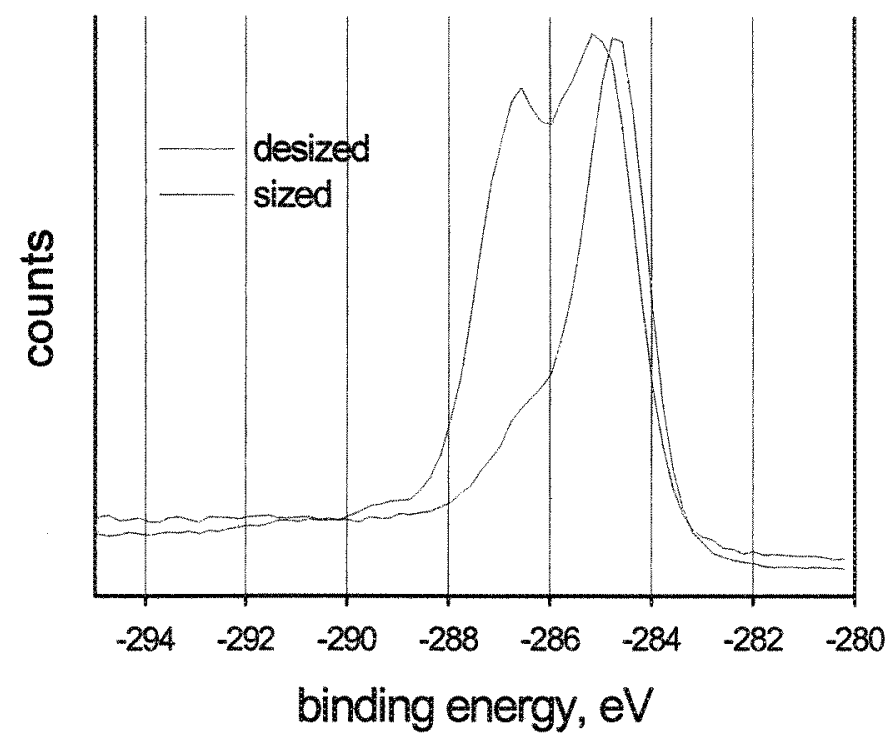

Figure 9. $C_{1 s}$ Photopeaks for Toray M40J carbon fiber 
Resolved XPS data for desized M40J and M60J fibers are given in Table III. Surprisingly, the M60J shows a higher surface oxygen content than the M40J in the desized condition. Generally, the effectiveness of shear treatments on carbon fibers decreases with increasing fiber modulus.

Table III. XPS Results for M40J Carbon Fiber

\begin{tabular}{|c|c|c|}
\hline Moiety & M40J Desized & M60J Desized \\
\hline$\%$ C-C & 72.2 & 70.4 \\
\hline$\%$ C-O & 14.7 & 13.3 \\
\hline$\% \mathrm{C}-0 \mathrm{O}$ & 0.7 & 0.9 \\
\hline$\% \mathrm{O} 1 \mathrm{~s}$ & 12.5 & 15.3 \\
\hline
\end{tabular}

In order to check the consistency of the desizing process, a $1 \mathrm{~kg}$ roll of desized M40J carbon fiber was analyzed using XPS for surface chemistry. XPS results from the beginning (section 1), center (section 2), and end (section 3) of the roll are given in Table IV.

Table IV. XPS Analysis of Large Batch M40J Desized Fibers

\begin{tabular}{|c|c|c|}
\hline Section & \% O & \% C \\
\hline 1 & 9.6 & 90.4 \\
\hline 1 & 11.9 & 88.2 \\
\hline 2 & 14.1 & 85.9 \\
\hline 2 & 13.0 & 87.0 \\
\hline 3 & 11.2 & 88.8 \\
\hline 3 & 10.5 & 89.5 \\
\hline
\end{tabular}

The percent oxygen results from Table IV show that the fiber surface contains $11.7 \pm 1.65$ percent oxygen. The standard deviation is near the normal error expected for XPS measurements, which shows that the desizing process is consistent over time.

\section{Single Filament Wetting}

Wetting measurements were used to determine the acid/base component of wetting work of adhesion for the sized and desized M40J carbon fibers. Work of adhesion measurements with methylene iodide were made to determine the dispersive component of surface energy.

Work of adhesion $W(\mathrm{mN} / \mathrm{m})$ measures the solid/liquid attraction as shown in Figure 2. W is calculated by Equation 1. As seen in Equation 1, W is determined by the weight of the entrained meniscus at the fiber/liquid interface:

$$
\mathrm{W}=\gamma_{1}+\mathrm{Mg} / \mathrm{p}
$$


where:

$$
\begin{array}{ll}
\gamma_{1} & =\text { liquid surface tension } \\
M g & =\text { wetting force } \\
p & =\text { solid perimeter. }
\end{array}
$$

$\mathrm{W}$ can be resolved into dispersive and acid-base components by wetting with acidic or basic probes (Equation 2).

$$
W=W^{d}+W^{a-b}
$$

The analysis is conducted by wetting with liquid pairs consisting of a dispersive liquid (methylene iodide) and a basic (formamide) or acidic (ethylene glycol) probe (Table 1). The dispersive energy of the solid surface is first calculated using Equation 3.

$$
\gamma_{\mathrm{s}}^{\mathrm{d}}=\mathrm{W}^{2} / 4 \gamma_{\mathrm{MI}}
$$

where:

$$
\begin{aligned}
\gamma_{s}^{d} & =\text { dispersive energy of the solid surface } \\
W & =\text { measured work of adhesion } \\
\gamma_{M I} & =\text { surface tension of methylene iodide }
\end{aligned}
$$

Then, the dispersive wetting work of adhesion, $W^{d}$, is computed using Equation 4.

$$
W^{d}=2\left(\gamma_{1}^{d}+\gamma_{s}^{d}\right)^{1 / 2}
$$

where:

$$
\begin{aligned}
& \gamma_{l}^{d}=\text { dispersive component of probe surface tension (literature value) } \\
& \gamma_{s}^{d}=\text { computed from methylene iodide wetting. }
\end{aligned}
$$

Then, $W$ is measured with an acidic or basic probe and $W^{a-b}$ resolved using Equation 5 .

$$
W^{a-b}=W-W^{d}
$$

A sample wetting trace for formamide on sized M40J is given in Figure 10. A similar wetting trace for desized M40J is given in Figure 11.

We know from the theory of wetting that the advancing wetting trace as the fiber penetrates into the wetting liquid is sensitive to low-energy sites and the receding wetting trace is sensitive to high-energy sites. The high-frequency chatter seen in Figures 10 and 11 is caused by alternating sites of different energies (micro-scale heterogeneity). Wetting results for the probe liquids on desized Toray M40J carbon fiber are given in Table V. 
Figure 10.

Formamide wetting trace on sized M40J Toray carbon fiber
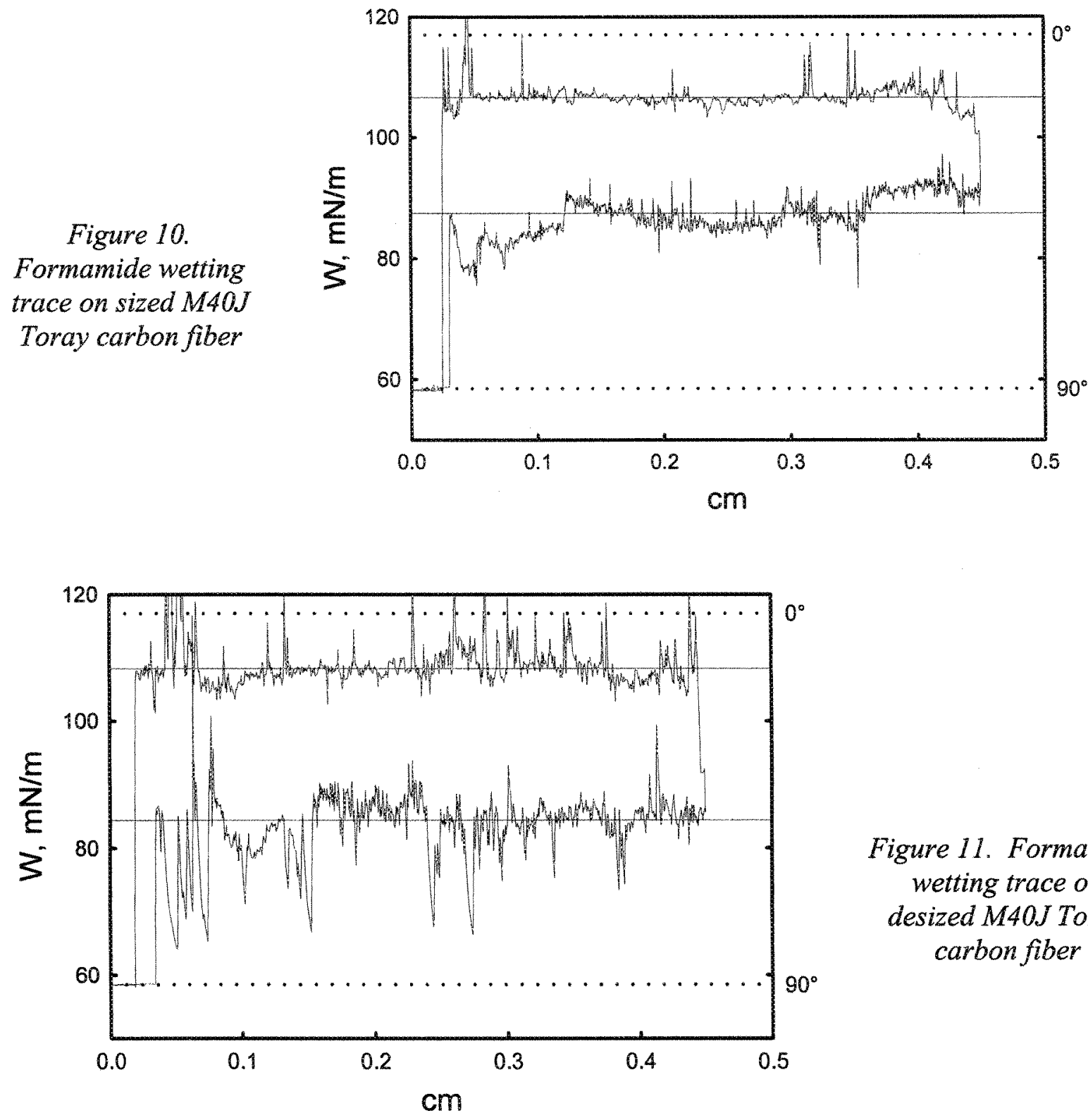

Figure 11. Formamide wetting trace on desized M40J Toray carbon fiber

Table V. Wetting Results for Desized M40J Carbon Fiber

\begin{tabular}{|l|c|c|c|c|c|c|c|}
\hline \multicolumn{1}{|c|}{$\begin{array}{c}\text { Wetting } \\
\text { Liquid }\end{array}$} & $\mathbf{N}$ & $\mathbf{W}_{\text {adv }}$ & $\begin{array}{c}\text { Std } \\
\mathbf{D e v}\end{array}$ & $\begin{array}{c}\mathbf{9 5 \%} \\
\mathbf{C I}\end{array}$ & $\mathbf{W}_{\text {rec }}$ & $\begin{array}{c}\text { Std } \\
\mathbf{D e v}\end{array}$ & $\begin{array}{c}\mathbf{9 5 \%} \\
\mathbf{C I}\end{array}$ \\
\hline Methylene lodide & 3 & 85.2 & 2.9 & 2.6 & 97.7 & 0.7 & 0.7 \\
\hline Formamide & 5 & 85.0 & 5.3 & 2.5 & 110.7 & 2.6 & 1.2 \\
\hline Ethylene Glycol & 4 & 73.3 & 1.7 & 1.1 & 92.5 & 3.0 & 1.9 \\
\hline
\end{tabular}


Calculated results for the acid-base work of wetting adhesion for formamide on sized and desized M40J and M60J carbon fibers are shown in Figure 12.

Figure 12. Wetting work of adhesion for formamide on Toray carbon fibers

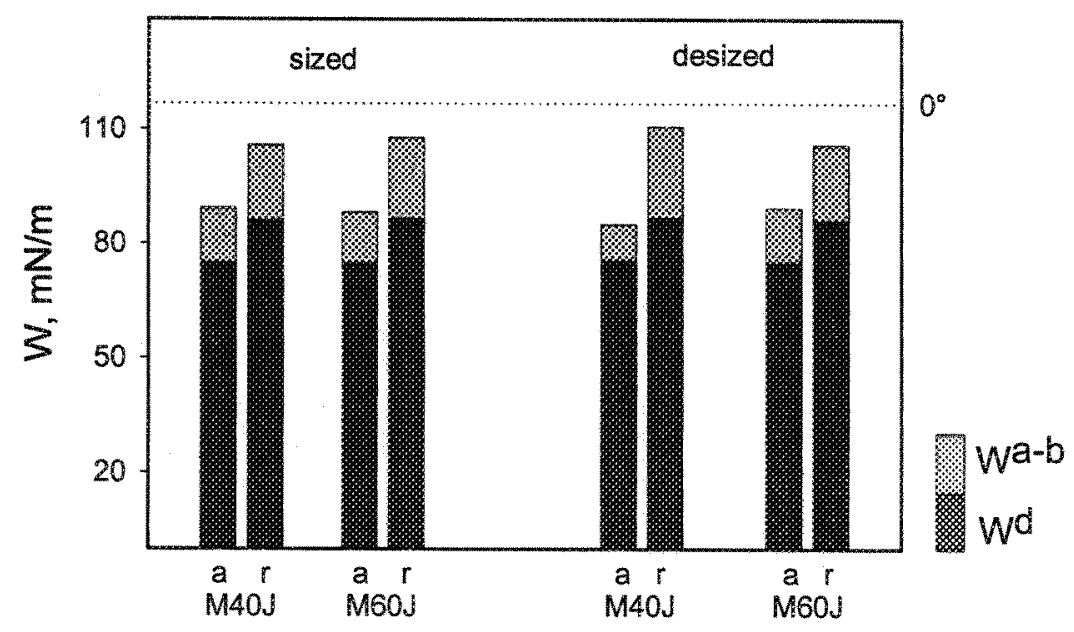

Similar results for ethylene glycol wetting are shown in Figure 13.

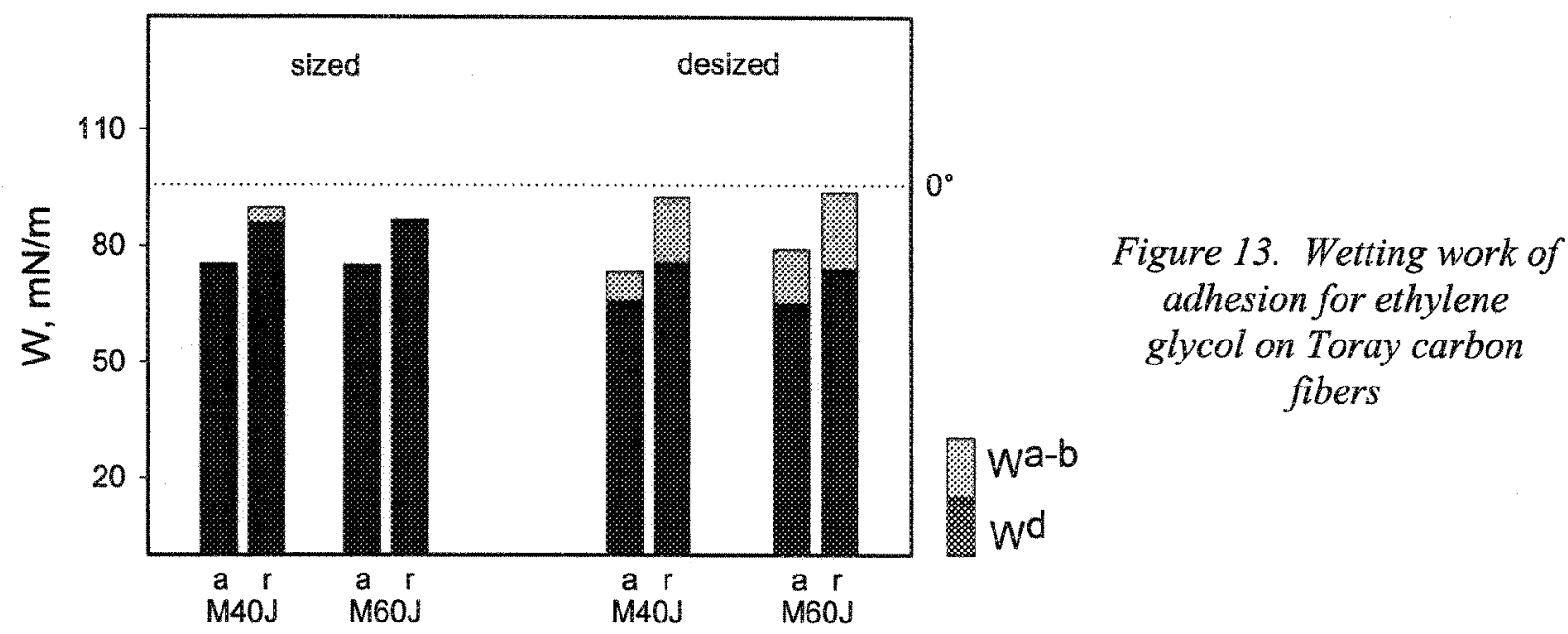

As seen in Figures 12 and 13, both the M40J and M60J fibers appear very similar in surface energy as sized or desized. This indicates that they contain the same size and have seen a similar shear treatment on the base fiber. Both the sized and desized fibers are mildly acidic (Figure 12). The sized fibers have no basic character; however, the desized fibers do exhibit a basic character (Figure 13) and are, thus, amphoteric.

Results for wetting work of adhesion on PMR-II-50 are given in Figure 14. 


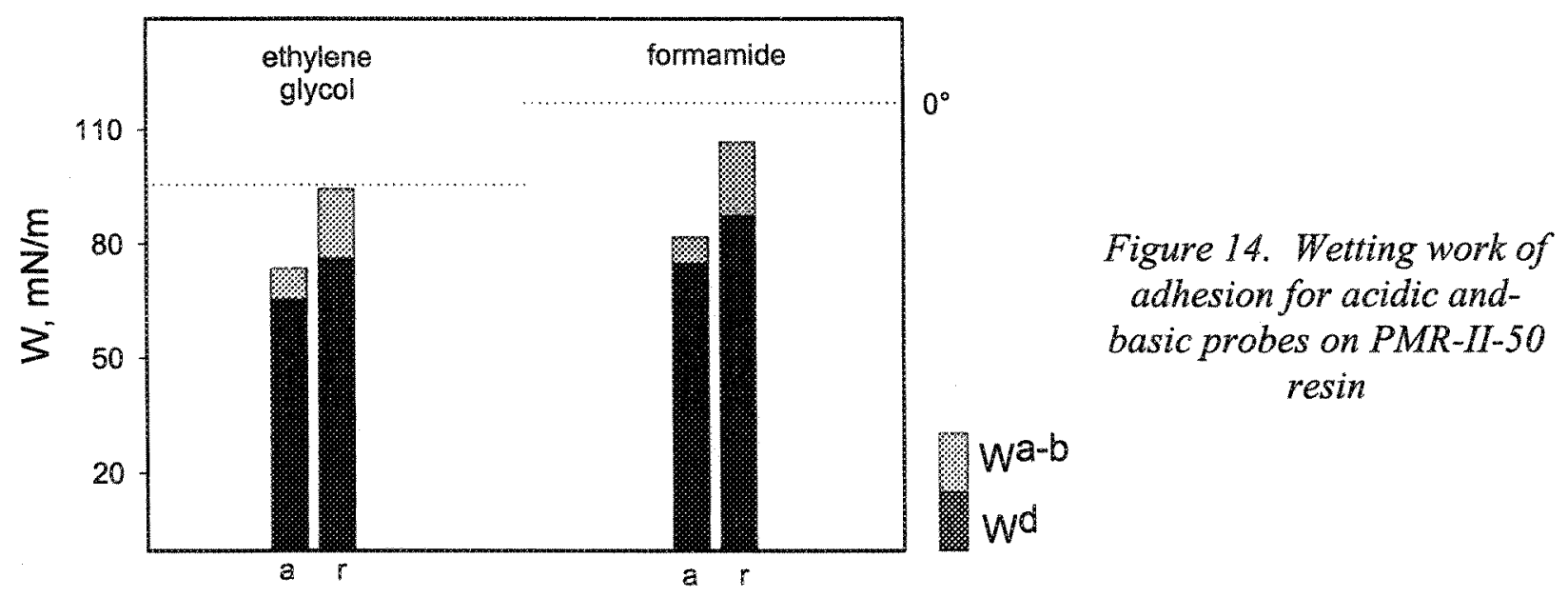

As seen in Figure 14, the PMR-II-50 resin is also amphoteric, indicating that it should adhere to the desized fibers by acid-base interactions at the interface.

\section{Finished Fiber Characterization}

The appearance of the as-finished fiber surfaces is shown in Figure 15. The finish goes on in a uniform coating due to the excellent film forming nature of the PMR-II-50 polyimide resin.

An XPS survey spectrum of the desized and refinished M40J fibers is shown in Figure 16. The strong fluorine peak from the PMR-II-50 polyimide in the finish is readily evident in Figure 16. Figure 17 shows an XPS survey spectrum for the finished M40J fibers after a 1 hour reflux in methanol. The strong remaining fluorine peak in Figure 17 shows that the finish, including the PMR-II-50 polyimide resin is well bonded to the M40J fiber surface.

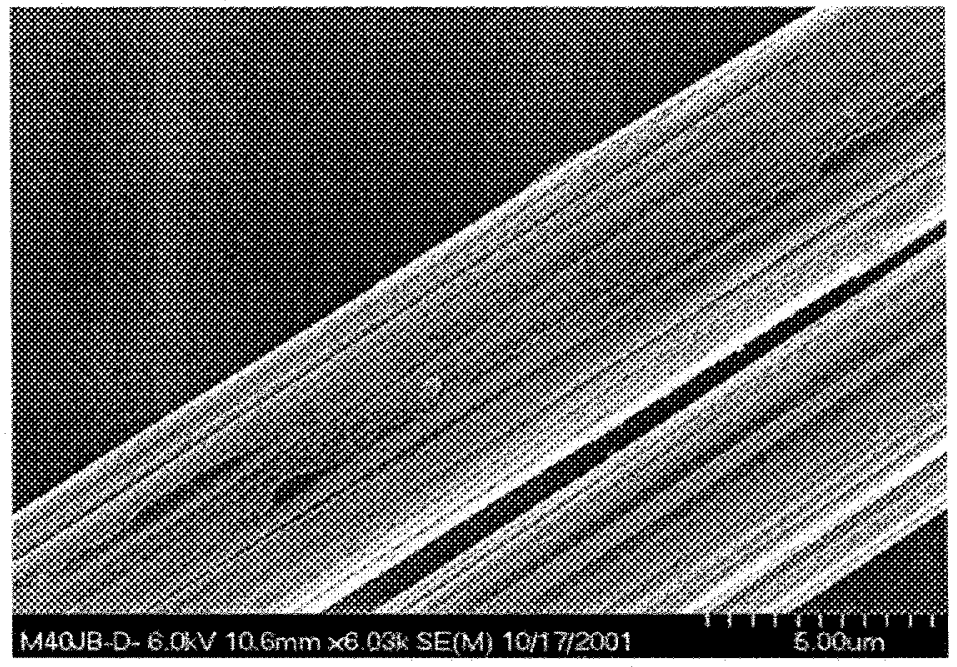

Figure 15. Appearance of finished M40J carbon fiber 


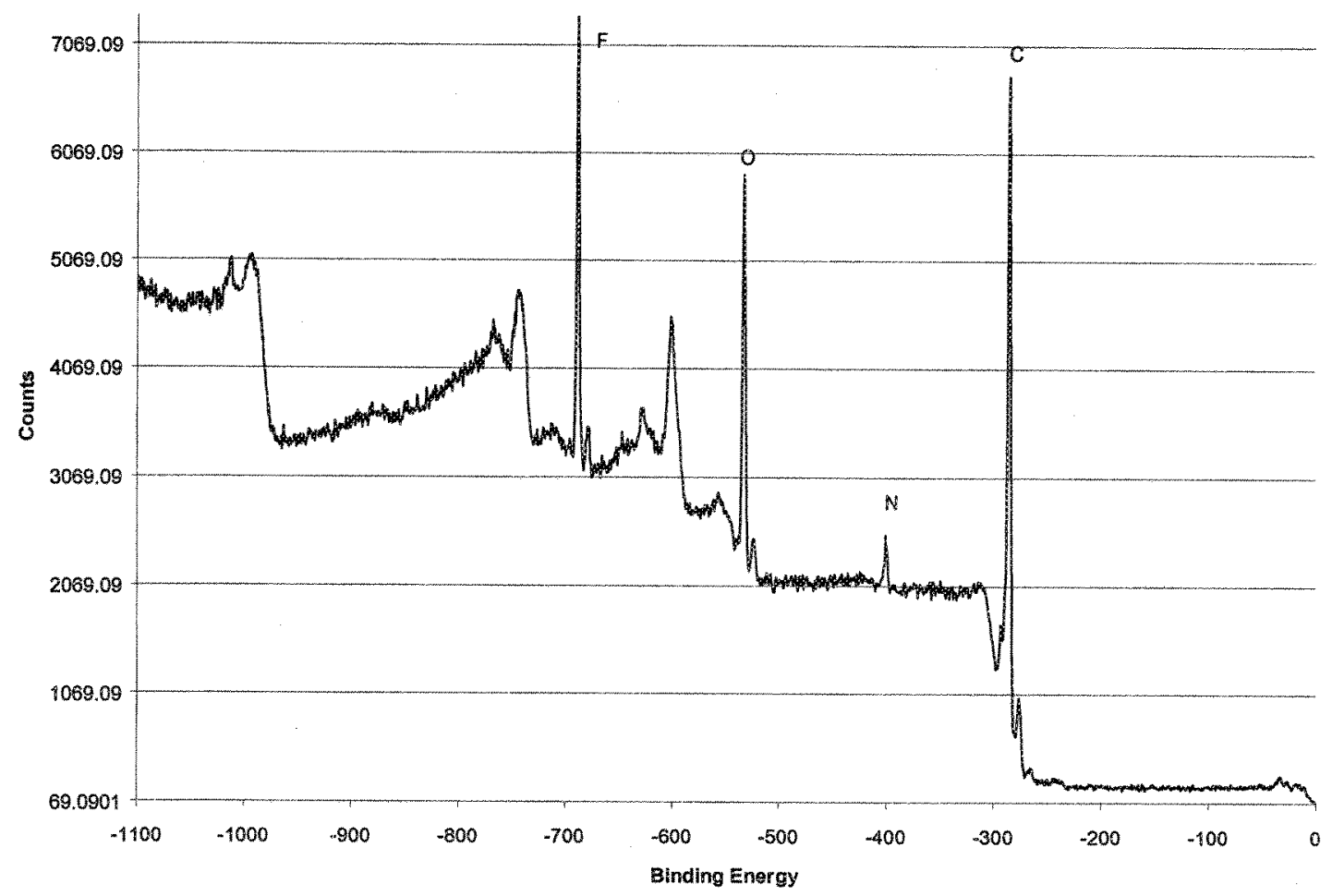

Figure 16. Survey XPS spectrum in eV of finished M40J carbon fiber

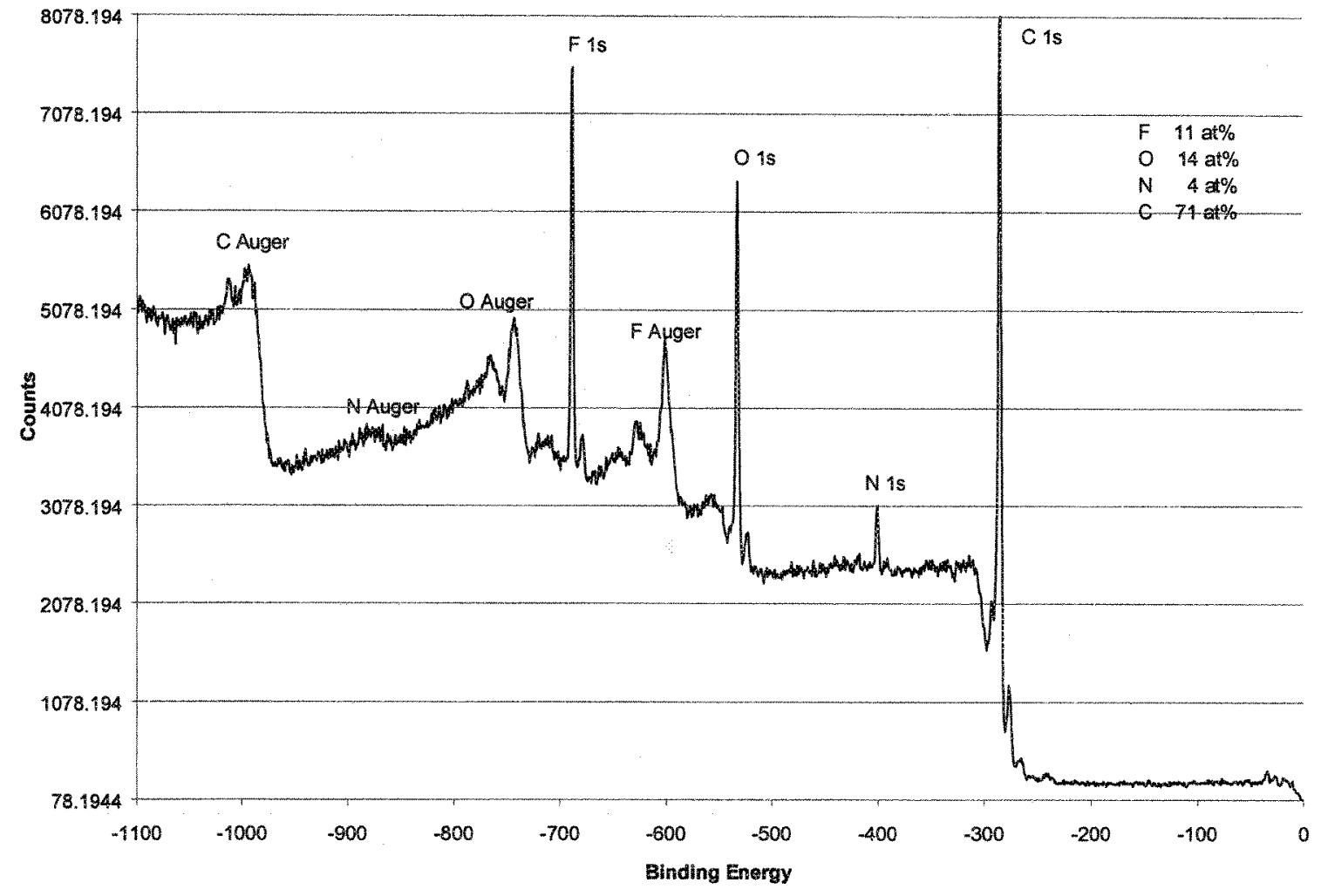

Figure 17. Finished fiber survey spectrum in eV after 1 hour methanol wash 
The XPS data on the finished fibers compared to PMR-II-50 polyimide resin is given in tabular form in Table VI. Only 13\% of the surface fluorine in the finish was removed by the 1 hour methanol reflux. Methanol is an excellent solvent for PMR-II-50 and is usually the solvent of choice for synthesis of the polyimide. As such, the large amount of residual resin remaining on the fiber surface is an indirect indication that the finish is chemically bonded to the M40J carbon fiber.

Table VI. XPS Elemental Analysis of Finished M40J Carbon Fibers

\begin{tabular}{|c|c|c|c|}
\hline Element & \% As Finished & \% After MeOH Wash & \% in PMR-II-50 \\
\hline $\mathrm{F}$ & 12.6 & 11.0 & 18.1 \\
\hline $\mathrm{O}$ & 16.2 & 14.0 & 10.4 \\
\hline $\mathrm{N}$ & 2.9 & 4.0 & 5.5 \\
\hline $\mathrm{C}$ & 68.4 & 71.0 & 66.1 \\
\hline
\end{tabular}

\section{Composite Laminate Characterization and Aging}

Thermomechanical characterization data for the three laminate types showed matrix Tg's at approximately $390^{\circ} \mathrm{C}$. Microcracks and void content of the as-fabricated laminates are given in Table VII. The different fiber surfaces lead to a wide range of microcrack densities, with the low-temperature sizing being the highest. A range of void contents were also observed with the refinished laminates having more than twice the voids of the laminates with sized fibers.

Table VII. Measured Microcracking and Void Content of As-Fabricated Laminates

\begin{tabular}{|c|c|c|c|}
\hline $\begin{array}{c}\text { Fiber } \\
\text { Treatment }\end{array}$ & $\begin{array}{c}\text { Microcracks/ } \\
\text { Cross-Section* }\end{array}$ & $\begin{array}{c}\text { Void Content, } \\
\text { \%* }\end{array}$ & $\begin{array}{c}\text { Fiber Volume } \\
\text { Fraction }\end{array}$ \\
\hline As-Received Size & $291 \pm 16$ & $2.1 \pm 0.2$ & $58.5 \pm 0.7$ \\
\hline Desized & $63 \pm 29$ & $3.5 \pm 1.4$ & $59.3 \pm 1.2$ \\
\hline Desized, Refinished & $120 \pm 6$ & $4.4 \pm 1.7$ & $54.7 \pm 2.9$ \\
\hline * Average of three measurements at three locations
\end{tabular}

Thermal aging weight loss data given in Figure 18 shows the desized laminates to be the least stable while the laminates with refinished fibers exhibited the lowest weight loss, which is an indication of improved TOS imparted by the reactive finish. 


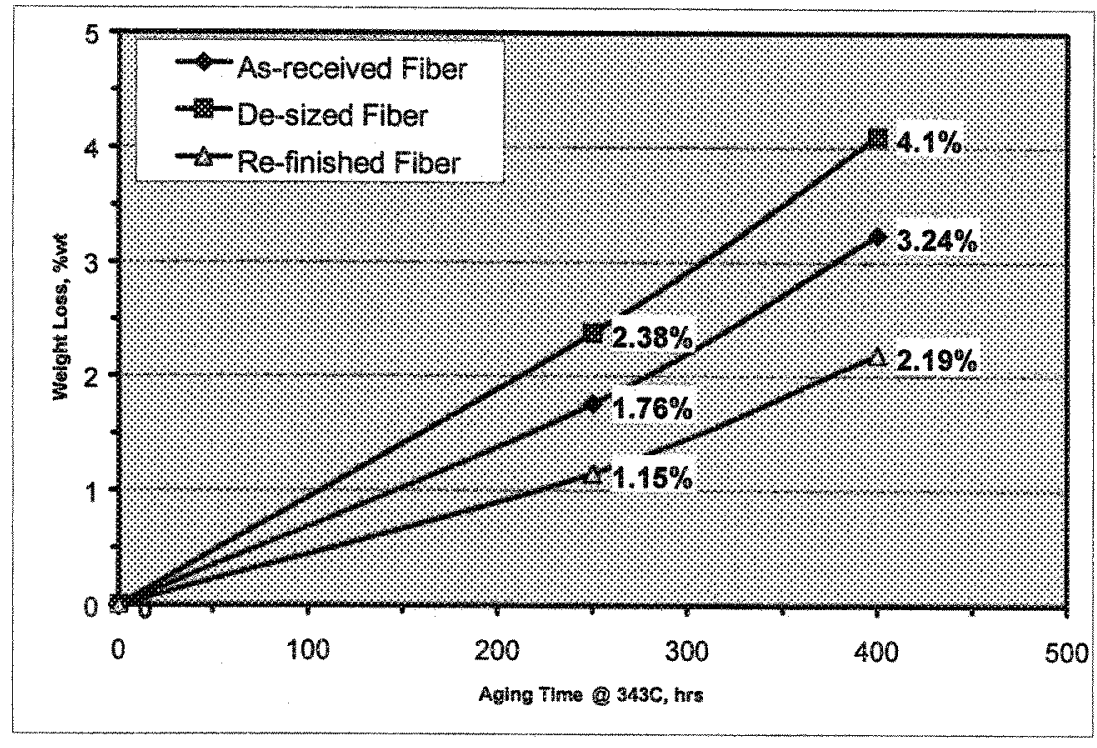

Figure 18. Weight loss vs time for $343^{\circ} \mathrm{C}\left(650^{\circ} \mathrm{F}\right)$ aging as a function of fiber treatment

\section{Composite Mechanical Properties}

Tensile shear and short beam shear tests were run on specimens from each of the laminates asfabricated and after thermal aging for 250 and 400 hours at $343^{\circ} \mathrm{C}\left(650^{\circ} \mathrm{F}\right)$. The $\pm 45^{\circ}$ tensile shear strengths as a function of percent return from the $\mathrm{C}$-scans are plotted in Figure 19. The data given in Figure 19 are summarized in Figure 20. These results show that the refinished fibers have a stronger and more thermally stable interface, whereas the desized fibers have the weakest and least thermally stable interface. The laminates made with fibers treated with the manufacturer's sizing are in between the other two treatments.

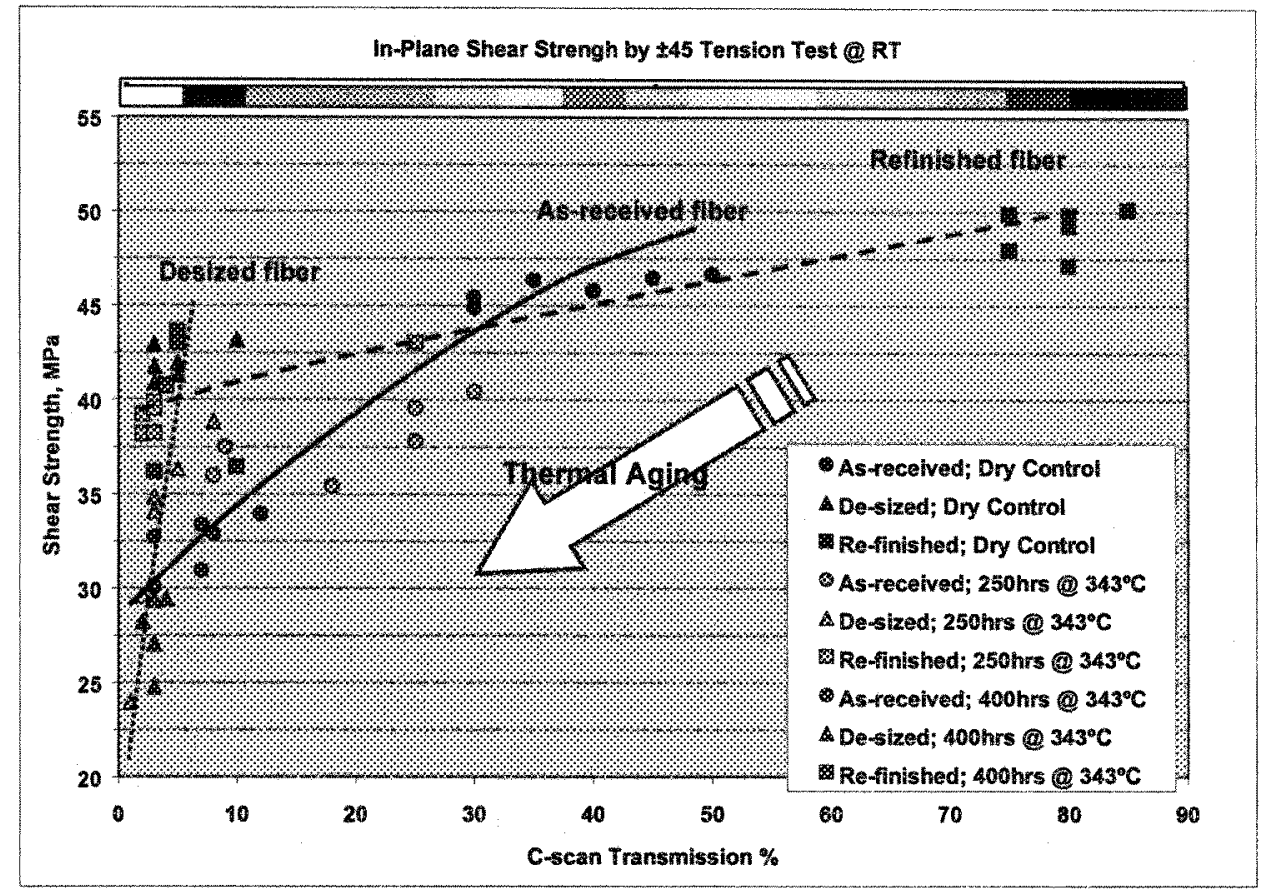

Figure 19. $\pm 45^{\circ}$ tensile shear strengths as a function of fiber treatment and thermal aging conditions 
Similar trends are seen in the short beam shear data given in Figures 21 and 22; however, the laminates with refinished fibers show a larger than expected drop after thermal aging (Figure 22).

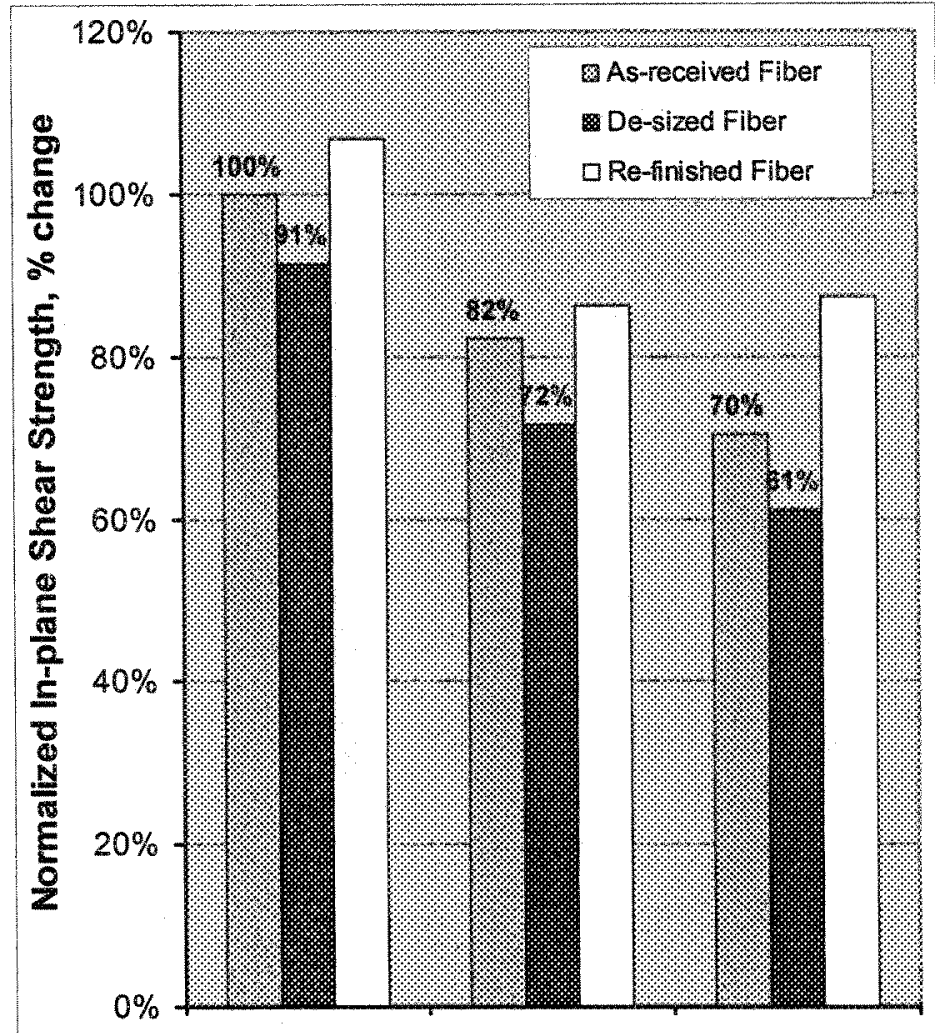

Figure 20. Summary of $\pm 45^{\circ}$ tensile shear strengths

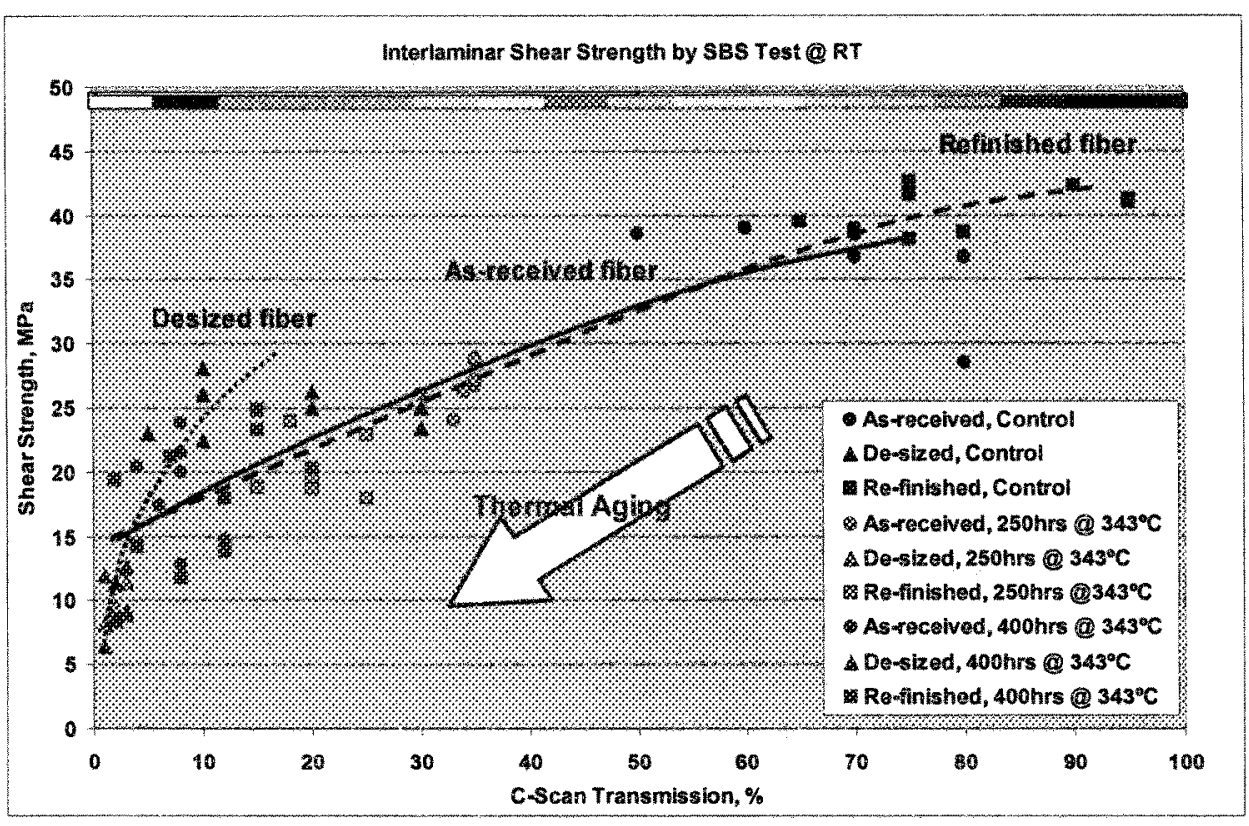

Figure 21. Short beam shear strengths as a function of fiber treatment and thermal aging conditions 


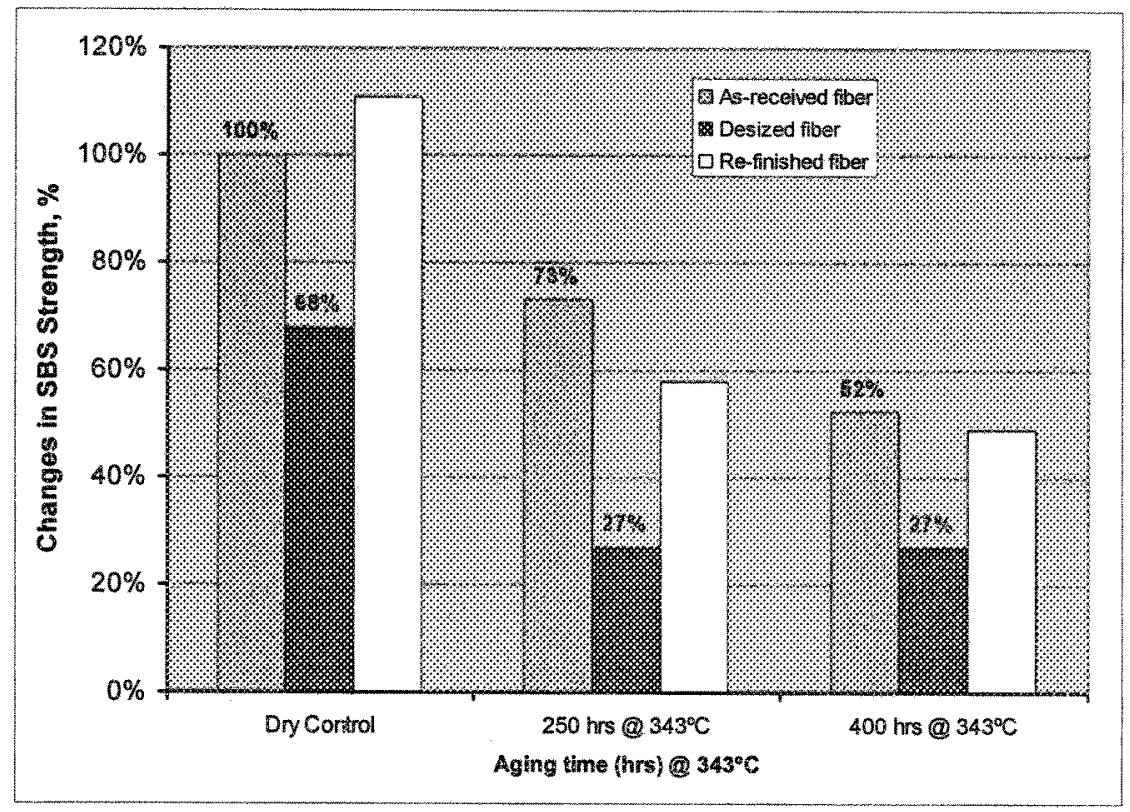

Figure 22. Summary of short beam shear strengths

\section{Blister Tests}

The equilibrium moisture uptake results showed that the Toray sized laminates absorbed $1.62 \pm$ $0.11 \%$, the desized $1.51 \pm 0.04 \%$, and the refinished $1.48 \pm 0.04 \%$. Moisture weight gain versus time is shown for the laminates containing Toray sized and desized/refinished fibers in Figures 23 and 24.

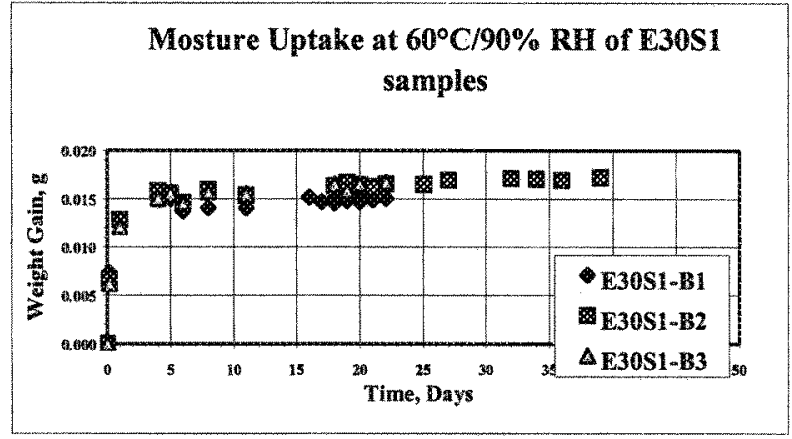

Figure 23. Laminate moisture gain with Toray sized fibers

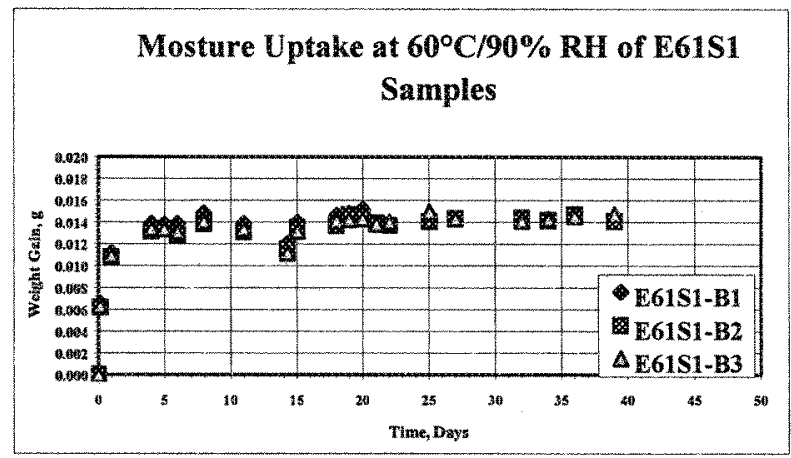

Figure 24. Laminate moisture gain with desized/refinished fibers

When subjected to the blister tests, the laminates containing the refinished fibers blistered at $260^{\circ} \mathrm{C}$ under both test conditions. Laminates containing desized fibers did not blister under any conditions, whereas the laminates with the Toray sizing only blistered under Condition 1 . The blister results are shown graphically in Figures 25 and 26. 


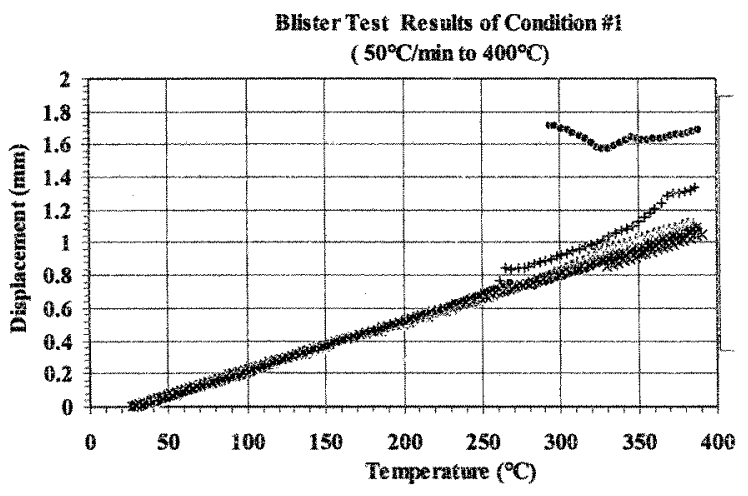

Figure 25. Blister test response for Condition 1

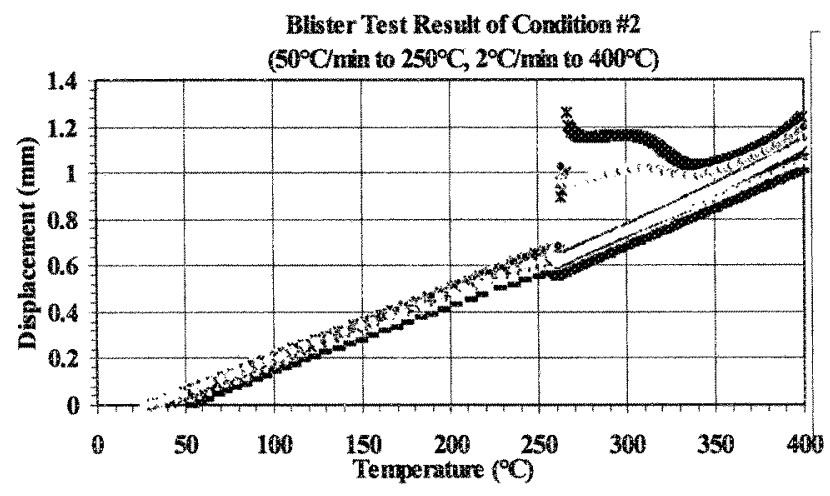

Figure 26. Blister test response for Condition 2

The specimens showing large displacements in Figures 25 and 26 are from laminates with refinished fibers. The microstructures of the laminates with Toray size and the reactive finish asfabricated and after blister testing are shown in Figures 27-30.

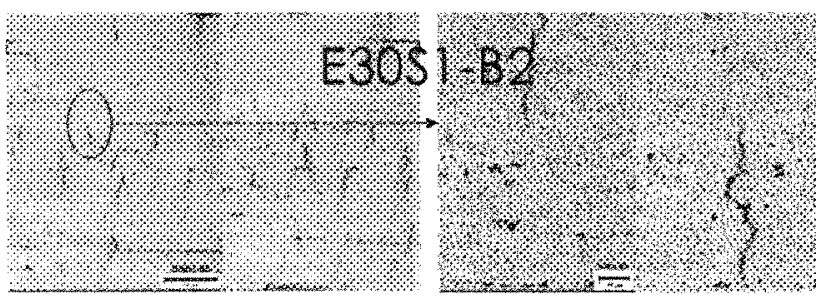

Figure 27. As-fabricated cross-section of laminate with Toray-sized fibers

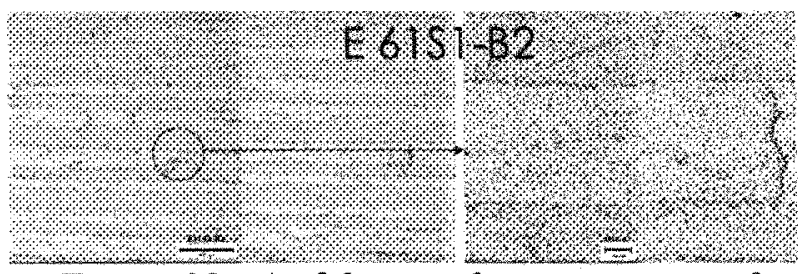

Figure 29. As-fabricated cross-section of laminate with reactive finished fibers

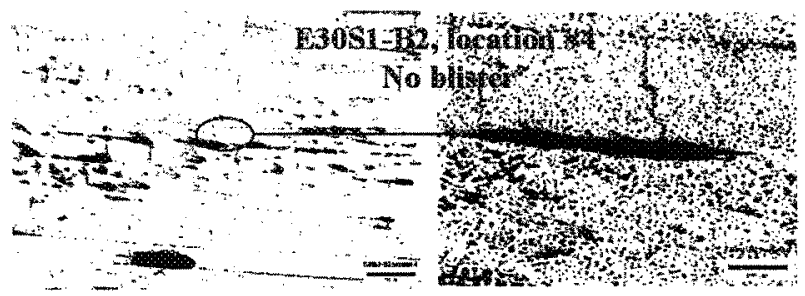

Figure 28. Toray-sized laminate after blister testing

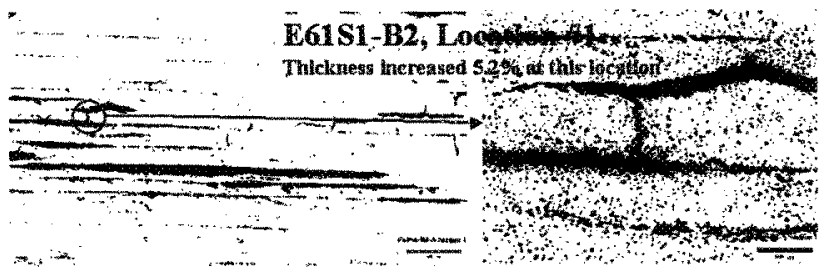

Figure 30. Reactive finished laminate after blister testing

Examination of the microcrack density data in Table II and the as-fabricated cross-sections in Figures 27 and 29 leads to the hypothesis that the better bonded laminate with the refinished fibers traps volatiles from moisture and matrix thermal degradation internally, causing the eventual blister formation (Figure 30). Where a network of microcracks exist that can provide diffusion paths out of the laminate as in the Toray-sized material, blisters do not form (Figure 28). This observation may also explain the large drop in short beam shear strength after thermal aging for the laminates with refinished fibers if internal delaminations were caused by trapping of matrix thermal degradation products.

\section{CONCLUSIONS}

This study characterized Toray M40J and M60J carbon fiber sizings and desized and refinished fibers and laminates fabricated with them. The Toray size coverage is very non-uniform and contains predominantly hydroxyl groups. A continuous desizing apparatus using hot chloroform 
and ultrasound produced clean fiber. Single filament wetting results show that the sized and desized surfaces are energetically and topographically heterogeneous. Formamide wetting shows that M40J surfaces and M60J surfaces display similar acidity whether sized or desized. Ethylene glycol wetting suggests that the size covers basic functionality that is uncovered by desizing. PMR-II-50 polyimide resin is mildly amphoteric, since $\mathrm{W}^{\mathrm{a}-\mathrm{b}}$ is small but finite for both acidic and basic probe liquids. The Toray fibers are highly striated on the surface and the surface is amphoteric with approximately $12 \%$ oxygen moieties present. A finish containing PMR-II-50 polyimide and a reactive coupling agent coats the desized fibers uniformly and chemically bonds to the fiber surface.

We characterized $[0,90,90,0,90,0,0,90,0,90,90,0]_{\mathrm{s}} 24-\mathrm{ply}$ composite laminates fabricated with a PMR-II-50 matrix and sized, desized, and desized/refinished fibers and then they were thermally aged at $343^{\circ} \mathrm{C}$ and tested in $\pm 45^{\circ}$ tensile shear, short beam shear, and moisture blistering tests. Results show that the finish based on PMR-II-50 polyimide resin had fewer microcracks, exhibited less weight loss after thermal aging, and produced a stronger and more thermally stable interface. The better bonded material displayed a higher tendency toward blistering, however, which is, perhaps, due to internal trapping of volatiles. Use of these finishes provides a means for producing more durable composites for use in high-temperature environments, but environmental conditions that could lead to blister formation must be considered.

\section{ACKNOWLEDGEMENTS}

The authors would like to thank Thao Gibson and Brian Rice at the University of Dayton Research Institute for conducting the moisture blistering tests. We would also like to acknowledge Frank Kerze for composite fabrication and Ojars Klans for specimen fabrication at NASA GRC. Tyler Wesley conducted the desizing process at Adherent Technologies.

\section{REFERENCES}

1. R. E. Allred, E. E. Shin, L. Inghram, L. McCorkle, D. Papadopoulos, D. Wheeler, and J. K. Sutter, "Thermomechanical Properties of M40J Carbon/PMR-II-50 Composites," Soc. Adv. Matl. Proc. Eng. Series, 47, 1187 (2002).

2. S. P. Wesson and J. S. Jen, Intl. SAMPE Tech. Conf. Series, 16, 375 (1984).

3. S. P. Wesson and R. E. Allred, in: Inverse Gas Chromatography, D. R. Lloyd, T. C. Ward, and H. P. Schreiber (Eds.), pp. 204-216, ACS Symp. Ser. No. 391, ACS Washington, DC, 1989.

4. R. E. Allred and L. A. Harrah, Soc. Adv. Matl. Proc. Eng. Series, 34, 2559 (1989).

5. J. A. Hinkley, W. D. Bascom, and R. E. Allred, in: Interfaces in Composite Materials, C. G. Pantano and E. J. H. Chen (Eds.), pp. 351-356, Materials Research Society, Pittsburgh, PA, 1990.

6. S. P. Wesson and R. E. Allred, J. Adhesion Sci. Technol., 4, 277-301 (1990).

7. R. E. Allred and J. K. Sutter, "Fiber Finish for Improving Thermo-Oxidative Stability of Polyimide Matrix Composites," Soc. Adv. Matl. Proc. Eng. Series, 42, 1291 (1997). 
8. D. T. Clark, in: Characterization of Metal and Polymer Surfaces, L-H Lee (Ed.), Vol. 2, p. 5, Academic Press, New York, 1977.

9. E. Eugene Shin, et al., "Design and Fabrication Issues of High Temperature PMCs for Aerospace Propulsion Applications," Soc. Adv. Matl. Proc. Eng. Series, 47, 356 (2002). 